Conti, E. (2021). Guides as forest experience co-creators: lessons learned at Fulufjället National Park, Sweden. In J. Albrecht (Ed.). Managing Visitor Experiences in Nature-based Tourism. CABI

\title{
Guides as forest experience co-creators: lessons learned at Fulufjället National Park, Sweden.
}

\section{Introduction: nature-based tourism, naturalness and humans}

Nature-based tourism (NBT) definitions generally relate to either resources or activities. Stokowski (2000) refers to both when defining NBT as experiences connected to natural areas or amenities, which serve as the base for attracting generalized recreational visitors. Fredman, Wall-Reinius and Grundén, in adopting an activity-based definition, define NBT as an array of "human activities occurring when visiting nature areas outside the person's ordinary neighbourhood" (2012, p.3). Bori-Sanz and Niskanen (2002) noted that, from the point of view of local suppliers, it is convenient to define NBT based on the economic value that leisure and recreation bring in a given natural area. Such definitions characterize nature-based tourism as a value-based demand for consumption of nature on the visitor's side, to which a commercial interest on the suppliers' side corresponds (Vespestad \& Lindberg, 2011). The correspondence is important to emphasise because NBT is seen, in the experience economy, as an experiential value exchange between human suppliers and tourists in the context of natural areas (Vespestad \& Lindberg, 2011). In fact, whereas objective natural resources themselves (or the activities connected to them) are often seen as the focus of definitions of nature-based tourism, the servicescape of products and services offered by human suppliers has critical importance in defining, valuing and selling tourism experiences in nature (Fredman et al., 2012; Margaryan, 2017). Supply-side actors such as guides, business owners, service workers, etc. are the stagers and presenters of the experience of "naturalness" which is offered on the market of the experience economy, and its attached values (Hansen \& Mossberg, 2017; Fredman et al., 2012; Vespestad \& Lindberg, 2011). In fact, nature-based tourism experiences are about the exchange of a valued "naturalness" even more than the physical natural resources, and most service providers in natural areas are not fully aware of how much the access to and the delivery of a valued naturalness depend on them (Fredman et al., 2012).

Recent trends suggest an increase in the demand of "human" factors of the naturalness of NBT experiences, such as culture, local sense of place, hostmanship, and high-quality services (Elmahdy et al., 2017; Hartman et al., 2019). These trends challenge the traditional, "purist" escapism from civilization normally attributed to NBT (Elmahdy et al., 2017; Dickinson, Hibbert \& Filimonau, 2016) and push further pressure on the management of human experience brokers. Several researchers underlined the vital role that dream, magic, well-being and spirituality play in experiences of naturalness, areas these that are traditionally underresearched (Heintzman, 2009; Varley \& Semple, 2015; Vespestad \& Lindberg, 2011). These 
reflect established themes of nowadays' experience economy, where experiences are conceptualized as combinations of multi-sensorial engagement, edutainment, dream, magic, pleasure, memorability, meaningfulness and authenticity to name few (Bryon, 2012; Gilmore \& Pine, 2007; Jensen, 2001; Pine \& Gilmore, 1999; Schmitt, 1999). On the other hand, such multifaceted ideas of naturalness do not find enough space in most of the tourism and serviceoriented research conducted in the context of the forest areas, particularly in Fennoscandia. Visitors' recreational and scenic/aesthetical preferences about natural resources (often collected through quantitative surveys) are translated into "values" of aesthetical or otherwise generalized nature and correspondent practical implications for aesthetical forest management (Gundersen \& Frivold, 2008; Pröbstl, Wirth, Elands \& Bell, 2010). This may lead to the limiting assumption that the experiential "naturalness" of the forest is about the aesthetics of scenic natural landscapes, with little other elements to consider. Gundersen and Frivold note that more than being just visually amiable, "forest landscapes are diverse and can be repositories of history, rituals, cultural and spiritual meanings, social and personal identities, and emotional memories" (2008, p.254). These values concur in creating a tourism "experiencescape" of the forest, as well as other natural areas, which makes it memorable, different, outstanding and competitive (Elmahdy et al., 2017; Hansen \& Mossberg, 2017; Hatman et al., 2019).

This book chapter explores the role of tour guides as human experience brokers of naturalness in forest areas. After outlining conceptual discussions around the role and tasks of the guide as experience broker, it moves from empirical findings to present the guide as a pivotal forest experience co-creator. Implications are discussed, with particular emphasis on how the guide's personal valuations of the forest, background and personal aims are reflected on the guide's pathfinding, storytelling and staging strategies, and how tourists being positively impacted by unexpected and different ways of valuing, mapping and interpreting the forest landscape.

\section{Guides: stagers of naturalness, interpreters and co-creators}

Tour guides have often suffered from stereotypes and trivialization (Hansen \& Mossberg, 2017; Weiler \& Black, 2015; Zillinger, Jonasson \& Adolfsson, 2012). According to Zillinger et al. (2012), the guide has been stereotyped as well as the tourist who participate in the guided tour, who has been depicted as a naïve, passive sightseer that walk pre-defined paths without questioning them. This is reflected in traditional views that see guiding as a unidirectional communication, presentation and staging activity (Weiler \& Black, 2015). However, conceptual advancements in the area of the experience economy emphasize the co-creation of experience value across the tourist experiential journey: consequently, tourists are now seen as active performers, interpreters and co-creators of the experience (Weiler \& Black, 2015; Campos, Mendes, Oom do Valle \& Scott, 2015; Ek, Larsen, Hornskov \& Mansfeldt, 2008). It is therefore suggested that the relationship between the guide and the guided is, in fact, a dialectical one, in which both subjects contextually participate, perform and co-create the guided experience (Overend, 2012; Ek et al., 2008) and its meanings (Reisinger \& Steiner, 2008). 
Tour guides have been defined as ambassadors, educators, instructors, entertainers (Hansen \& Mossberg, 2017), mediators and leaders (Galí \& Aulet, 2019; Cohen, 1985) and choreographer, among others (Jonasson \& Scherle, 2012; Overend, 2012). All these definitions well encompass the multi-layered brokering tasks of a guide. Moreover, Cohen (1985) defined the guide as a pathfinder, who has the spatial knowledge of the area which allow him/her to optimize and rationalize an itinerary to a destination (Galí \& Aulet, 2019; Reisinger \& Steiner; 2008) and to transform geographical sites and resources into valued sights and landmarks (Weiler \& Black, 2015). According to Christie and Mason, the guide "act as a conduit between the tourist and the place/local community visited" (2003, p.2) mostly in terms of leading the interpretation of the latter. Guides can, consequently, establish tourism discourses at destinations by presenting local cultures and places from a non-neutral point of view (Hallin \& Dobers, 2012; Dahles, 2002). This makes their role of passive mediators questionable and instead bring forth the necessity to consider the proactiveness involved in their role as leaders and interpreters (Reisinger \& Steiner, 2008). The agency of the guide in shaping the interpretation is, consequently, important to consider, as it might reflect external as well as personal agendas (Hallin \& Dobers, 2012; Reisinger \& Steiner, 2008; Dahles, 2002).

Guides are also defined as storytellers, and stories are increasingly valued in the contemporary experience-based tourism marketplace (Hansen \& Mossberg, 2017; Bryon, 2012). Storytelling leads to intellectual and emotional stimulation, and help in making tourist sites different, relevant, meaningful and authentic (Io, 2013). Bryon (2012) distinguishes between impersonal selling of common tourism imaginaries (what Reisenger \& Steiner, 2008 refer to as commodified assertions), telling specific facts and stories, and sharing of personal tales. "Relational guides" focus on the latter, making their storytelling more genuine and personal than crafted, romanticized or enhanced (as it is for "entrepreneurial" guides). At the same time, relational guides do not aim just at presenting knowledge in a distant way (as it is for traditional "official" guides). Finally, they do not aim only at hedonic edutainment (Bryon, 2012). Reisenger \& Steiner (2008) propose the Madrich as an alternative model for guiding, that oppositely from traditional "official" guides, does not rely on distant, commoditized or formal storytelling, but encourage reflections, dialogues, individual meaning-making and the establishment of authentic relationships between the place and the tourist identity. Hansen \& Mossberg (2017) connote the "guide plus" as the guide that, by doing so, exceeds the guide's basic role of instructor, performer, storyteller and leader.

Specifically, in NBT it is underlined the capacity of guided tours in inspiring tourists towards environment-friendly behaviour (Andersen \& Rolland, 2018; Reisinger \& Steiner, 2008; Weiler \& Davis, 1993), fostering, therefore, transformation and attitude change (Christie \& Mason, 2003). Unsurprisingly, sustainability and interpretation in tour guiding are the most discussed topics in NBT guiding (Black, Weiler \& Chen, 2019). However, service-based and marketing theories such as service quality, importance-performance and satisfaction are also dominant (Hansen \& Mossberg, 2017). This is again not surprising, considering that research has established that tour guides are critical in achieving high levels of satisfaction and impact greatly on the quality of a tourism experience (Galí \& Aulet, 2019; Hansen \& Mossberg, 2017; Pond, 1993). Consequently, there is a noticeable attempt by organizations in ensuring highquality guiding by pushing on the development of transferrable skills, in response to an 
increasingly competitive and refined marketplace (Hansen \& Mossberg, 2017; Bryon, 2012; Zillinger et al., 2012). Weiler and Black (2015) argue that new market trends and increasingly refined experience demands call for guides to respond by re-inventing themselves in the quest for delivering value to the tourist. As underlined by Vespestad and Lindberg (2011), the moment in which nature becomes the focus of commercialized tourism experiences, brokers of naturalness should respond to value-based demands of naturalness and organize their valueadding roles based on the "supposition (belief) of how the tourist want it, and hope it is appreciated" (2011, p. 565). The authors conclude that any brokering of naturalness should result from a "shared comprehension of the phenomenon among the provider, marketer and the tourist" (2011; p. 575).

"Transferrable" skills comprise high levels of local knowledge, communication and social skills, fluency in foreign languages (Cohen et al., 2002), creativity (Bryon, 2012) and interpretive effectiveness (Weiler \& Ham, 2001). Weiler and Black (2015) underline that the capacity to listen to others and engage in dialogues adds to entertaining and social skills, the moment in which the guide is portrayed as a co-creator. Valkonen, Huilaja and Koikkalainen (2013) argued that, having visitor satisfaction in mind, in the experience-based guiding "soft" feats related to personality are being weighted more than "hard" technical skills. This trend is defined by the authors as the personification of service work skills. On the other hand, when seen as service givers/sellers, guides are asked to sell their personality, "since the physical and intellectual capital of the employee is turned into economic capital by the service organizations, and made to serve their interests" (Valkonen et al., 2013, p. 229). The wrong turns that this might take for the employee, such as personal insecurity and commoditization of human relationships, can, in turn, be reflected on the visitor experience and its authenticity, particularly if the interpretive agencies of the guide and the visitors are constrained as a result of excessive commoditization (Valkonen et al., 2013; Reisinger \& Steiner, 2008). Excessively routinized and staged guided tours presented by Dalhes (2002), and related to political control, might as well be the result of a trend- and market- based control imposed by external stakeholders on the guide.

\section{Case area and methodology}

The following reflections on the role of tour guides in the experiences of naturalness are based on empirical research conducted by me at Fulufjället National Park, Dalarna County, Sweden.

The Fulufjället National Park covers the Swedish side of the mountain Fulufjället. Fulufjället National Park is advertised as offering "an exceptional alpine experience" on its official website. Whereas the mountain has certainly a primary role in framing the nature of the experience at the park, a vital spot is reserved as well for the primaeval forest at the mountain's feet. Although several natural landmarks are advertised by the local visitor centre, the two main landmarks reachable by foot from the park's centre are Njupeskär (Sweden's tallest waterfall) and Old Tjikko (a clonal tree whose roots are estimated to be 9550 years old, advertised normally as one of the world's oldest tree). Both these landmarks are part of the guided tours that are regularly scheduled from the visitor centre. Such guided tours (the ones assessed by this chapter) are actually advertised as "guided tour to Old Tjikko". 
The research was conducted on two separate occasions during the summer of 2018. I conducted inductive ethnographic fieldwork by joining guided tours with two guides and by conducting unstructured interviews with participants during and after the tours. I also conducted semistructured interviews with one of the guides who conducted the tour (Alex) and another guide who also work at the park (Lia). The findings discussed in the following section are based on the interviews as well as on the ethnographic field notes, which were interpreted and analysed following an inductive thematic analysis (Clark, Braun \& Hayfield, 2015). Both the guided tours and the interviews with the guides were conducted in English. Both guides are Swedish, but their command of English was good as they normally conduct tours in English. Tourists interviewed during the ethnographic fieldwork were of various nationalities, but as they joined tours in English, their language skills were sufficient for the scope of the unstructured interviews. Yet, both occasional exchanges made in their native language and comments in Swedish or Norwegian exchanged with the guides could not be assessed, and this is recognized as a limitation.

\section{Findings and Discussion}

\section{Pathfinding}

Pathfinfing is normally associated with brokering new spaces, and studies often assess its impact on the visited areas by looking at the differences between the itinerary that is followed by guided as opposed to non-guided tourists. Galí and Aulet, (2019) found that tourists visiting urban heritage sites tended to follow similar itineraries and stop at the same attractions, with most of the spatial differences between guided and non-guided itineraries being related to route optimization and the avoidance, during the tour, of "off the beaten track" attractions visited by non-guided tourists.

Participating in guided tours to Old Tjikko, I observed a very different situation. The guides were pathfinders in the most literal sense because they drew new paths that were very different both spatially and temporally to the ones followed by non-guided tourists. Most non-guided tourists were following the beaten or paved paths, stopping mostly in resting areas. The guides, quite literally, went "off the beaten paths", venturing in the forest and stopping when they could identify a site that they personally valued. These paths "off the beaten track" introduced guided tourists to new, unbeaten landmarks, drawn on the landscape by the guide's route, and composed by trunks, trees, undergrowth, lichens, mushrooms and bugs, often found and showed by the guide in hidden corners of the forest, which the guide knew well. The suggestion that tourists cannot interpret the alien worlds they visit or will have a less rich experience if they are not explained what they are experiencing, challenged by Reisenger and Steiner (2008), could be instead confirmed on the field. In fact, tourists were introduced to an enclave, separated by non-guided tourists, rich of new interpretations of a forest landscape at least partly unknown, which enriched their experience (Hansen \& Mossberg, 2017).

The pathfinding guide emerged not as the one concerned merely in rationalizing a path, reaching a destination ("Old Tjikko") and come back safely (Galí \& Aulet, 2019; Hansen \& Mossberg, 2017). Conversely, he/she was closer to the "broker" of physical access described 
by Weiler and Black (2015). Guides physically manoeuvered tourists to new places, presented, performed and interpreted them and their meaning according to the guide's background and personal forest valuations. Lia stressed the point when she said that guides should participate in each other's tour more often:

"what do you say here, where do you stop, what do you do, and try to learn from each other, but that is more learning about what we can find along the way. [...] we have like, another guide that is more a specialist in lichens and stuff like that, and looking for species that show that this is a valuable forest, and I have never had that kind of training, so, for me to go with him is a really good thing."

Lia's quote illustrates that different forest resources are normally valued as tour landmarks depending on the guide's background, knowledge and staging strategies. For instance, Alex's expertise in forest biology allowed him to stop at specific sites and illustrate their value differently from other guides, who follow different itineraries and stop in different areas. If Alex's thematic tour brings him to go to a specific point by the river, to find a specific type of lichen and to show tourists how its colour change by pouring water on it, Lia's thematic tour brings her to sites with particularly large trunks, that the visitors can try to encircle. Guides' personal pathfinding brokered this way the physical access to Old Tjikko,and certainly influenced the brokering of different understandings and different emotions (Weiler \& Black, 2015). Alex found important to point out that, although the name of the guided tour and its final destination relate directly to Old Tjikko, the route itself and the related value landmarks are actually the tour's focus: "most people that come here, they have expected old Tjikko. And when we get to Old Tjikko, they probably lost it on the way, I hope, because I hope that my stories, my storytelling is giving them something else to think about during the time we are doing this guided tour". It is interesting to note that few of the participants mentioned Old Tjkko itself among the most valuable things experienced during the "guided tour to Old Tjkko".

\section{Reflective storytelling}

If the physical brokering of the guide was not made in the name of a route rationalization, it was also not made according to an assessment of tourists' expectations, or to "enhancing" an Old Tjkko experience based on visitor demand, or a supposition about it (Vespestad \& Lindberg, 2011). Instead, the guide's thematic storytelling was what connected the valued sites into new paths (Hansen \& Mossberg, 2017). The value of storytelling and themes in the experience economy has been widely recognized by the tour guiding literature (Hansen \& Mossberg, 2017; Bryon, 2012), but again, stories and themes employed by the guides were more than just "enhancing" tools, implemented on the basis of demands and trends. Instead, they were connected to guides' personal valuations and ontologies of the forest. Alex's storytelling, for example, is normally about time, and "how important time is to develop the biodiversity of the functioning ecosystem [...] I want people to understand that time is something we human beings have developed in a way that it would be just for us. Because time is everything. That's why it is nice to show them the life cycle of a tree".

Stories are certainly a way to broker empathy and authenticity (Weiler \& Black, 2015). Bryon (2012), Hansen and Mossberg (2017) and Reisinger and Steiner (2008) argue that whereas 
traditional guides' storytelling is distant, commodified and/or impersonal, guides who are informal and share personal stories can establish authentic relationships between them, the tourist and the place, enriching meaning-making, extraordinarity and memorability.

Lia and Alex, who Bryon (2012) would qualify as alternative and relational guides, aim at doing just that. To begin with, none of them believes they are romanticizing or glamorizing nature in any way during their tours. Lia stated that nature does not need romanticization: "No, I think it is like that in itself. I think you can make it fantastic by going really close, and talking about these really small organisms, that sort of play a big role, or has a very specific living conditions, then they are like, amazed anyway, you don't have to be like 'WOW',. Alex referred to "the magic of the ecosystem" and mentioned several times how "sacred" is the forest according to him. But magic itself is not something that is glamorized in order to add consumption value to nature, or the guided tour experience: "You don't have to romanticize but to tell them, to get them to understand that life is nothing for our cause, or for the things that we like. Life is something special for everything that is on this planet.".

"Magic" here is just the resulting feeling of a way of valuing the old-growth forest which connects deeply to the guide's lifeworld. The sensation of "Magic" is not a goal, but a vehicle that allows tourists to get closer to the guide's forest valuation: "if they somehow can take it to their minds or hearts, I think they will actually be more concerned about we as human beings on the planet, be more careful of doing bad stuff. I think that's what I want to achieve with my guided tour [...] We all need to share this planet together. With all the others. Plants, lichens, mosses."

Alex shared often personal stories, associating trees to memories of relatives (Bryon, 2012). This helped him in humanizing the landscape, and at the same time in underlying his bonds to it. He did not hesitate to provide disenchanted and negative views, when required, for instance when a tourist was stunned by the view from the mountain on what seemed to be endless kilometres of forests, which Alex described merely as "cultivated land". A similarly disenchanted view was shared by Lia: "would you call a field of wheat a meadow?[...] Then why do we call a field of tree a forest?".

Lia, who usually talks about local folklore during her guided tours, mentioned that "when you walk through the old-growth forest, you can imagine like walking there in dusk or dawn, all of these trees that are falling down and everything, of course with the imagination you can see trolls, and you can see fairies". Yet, her aim is not to disneyfy the forest, or to make it more extraordinary, but to educate participants about the "cultural heritage" of people who inhabited the forest and their old fairytales stories. These stories concur to her aim to inspire visitors being "humble" towards the forest. She stressed that she is not inventing anything to make it more appealing: "what I want them to do is to try to get something started in their head, another way of thinking [...] I am part of nature, what I do has an effect of the rest of the world. You feel very small, but still what you do can have an effect". She would like her groups to leave with such feelings. Alex specified that he hopes that when they are driving home, they look around the vast forest landscape of Sweden and say "hey, I don't see any old trees, where are they? Then they are involved again". The aim is therefore that 
the "involvement" is expanded outside the borders of the tour, or even the national park, into an improved, world-embracing environmental awareness (Christie \& Mason, 2003).

Not all the participants, at the end of the tour, mirrored the abovementioned transformational aims in their reflections. When asked about what they found most valuable about the tour, several participants mentioned an increased environmental awareness, with comments such as "when I come home I am gonna use less plastic" and "It changed my way to look at the woods". Yet, these coexisted with others holding more generalized appreciations for increased knowledge about the forest ecosystem and its life cycle, and comments about enjoying the views, the peace, the calm, the family time and the clean air. Overall, however, visitors were highly satisfied, when not galvanized, felt secure and had no complaints.

Knowledge and choreography

Although a critical part of the guide's storytelling relates to knowledge (Chritstie \& Mason, 2003), educating is not interpreted by the guides as a formal and/or distant transmission of knowledge (Bryon, 2012). Lia mentioned that "I am not so interested in like, 'oh, you should learn all about this species', maybe it is not important that they learn everything". Instead, new knowledge is associated with experiencing a new way of thinking: "to get them to see other things, and, like, 'experiences, ah! Wow, I didn't know that!'Like they found out something new".

Alex sees knowledge as paired with passion, personality and social skills (Valkonen et al., 2013; Welier \& Black, 2015), which all concur in transmitting a story: "at first you have to have some kind of knowledge yourself, and you try to give a story to anyone [...] Then of course as a guide you need to have a heart for the things you do, and the things you talk about. Without the heart and soul, you are nothing. It's like, you know, a musician who doesn't have a heart to, you know, stand and make the music.. he will never make any music. [...] Then of course social skills are really important. That you can see everybody in the group" and you allow everyone "to be part of this involvement of being guided".

Despite the literature is moving from the concept of the guide as an entertainer (e.g. Weiler \& Black, 2015; Reisinger \& Steiner, 2008), Alex considers entertaining while educating, "really important". During the tour, he showed how clean the water of a river was by personally filling a bottle, drinking it, showcasing refreshment and offering it. He also passionately spat water on specific lichens to show how their colour change due to humidity, which provoked laughs in the participants. Light humour was often sought and contributed to making knowledge less impersonal (Bryon, 2012). The explanation of a lichen used in the past to kill wolves ended with "so you know now and you can give it to someone you do not like". An old tree was compared to an old man that goes shopping and mimicked physically. He practised multisensorial engagement (Weiler \& Black, 2015): "you saw that I was spitting water on the lichens because I wanted them to see the metamorphosis of this lichen from being dry to being good-looking when it's wet". Taking on the charcoal, giving them 200 years of history, and you can actually see it, you can touch it. If people see that stuff it is some kind of entertainment, but it is also trying to reach their minds" and their acknowledgement, involvement: "because if they are not involved, they will not listen.". Several participants were impressed by Alex's 
enthusiasm and passion, and one valued particularly the experience of drinking clean water from the river while crossing it. Lia's fairytale stories are moments of edutainment for the kids, because if they are encouraged to chase trolls, then they can notice how big are certain roots, especially if Lia makes sure they do. In line with her tour theme of "feeling humble", she normally hugs big trees to show that she cannot encircle them with her hands.

The role of the guide as a choreographer is stressed out in the literature (Weiler \& Black, 2015). Yet, it is important to underline that in this case such choreography is not aimed at satisfying the tourist hedonically (although that was observed to be an effect) and that the point is not the choreography itself. The metaphor of the guide as a theatrical actor, employed at times in the literature, might be misleading because it suggests the passive role of someone merely concerned in performing a script. The choreography is part of a life story and the story, as shown above, is guide-based, guide-valued and transformation-based (Christie \& Mason, 2003). The guide, more than being an "enhancer", is what Weiler and Black (2015) call and empathy broker, meaning that the aim is to bring the visitors to feel empathy, affinity and awareness for the forest according to the guide's personal valuation, which is unveiled by the story and how the story is choreographed. The point is to provide not only cognitive but also affective understanding, and room for meaningful contemplation.

Expectations and demand trends were not influencing the choreography in use as much as how such choreography was able to better deliver a valued story. Alex made this point clear: "I actually don't think about that [expectations] at all, [...] if they only think about their expectation, they will never listen to what I tell them [...] I'd like to change the expectations. Create something else than they expected". Lia agrees on this point: "it is not just 'yeah we are just going here, looks nice, bye' [...] "the main objective is that the visitor should have got something extra when they were here".

\section{Co-creation}

Acknowledging the movement of the guide's role from leader and choreographer to co-creator, Weiler and Black (2015) argue that flexibility, transparency and openness to dialogue become critical aspects of the guide, who is asked to provide avenues to let the tourists be a co-creator. All guides provided time for the group to discuss the tour on their own and to encourage personal reflections during and after the tours. To begin with, the tour's structure allowed visitors (particularly couples and families) to talk to each other while venturing in the forest, especially while walking between the different stops. These talks were often related to sharing surprise and reflections with the significant other(s) on the new knowledge acquired, as well as its meaning. Moreover, visitors were fairly free to stay behind or to independently walk in the proximity, e.g. to play with kids, admire a nice view, or let the dog roam free for a while, creating their personal valued moments. The latter was particularly important for a participant whose main aim to visit the park was to "take a lot of energy for the rest of the year" for her and her dog which was seen as "part of the family". In no occasion the tours felt rushed.

Lia and Alex confirmed that they are always flexible about suggesting participants where to take good pictures when they notice interested visitors. Lia underlined that during her tours she tries "to have a dialogue, not like, I am guiding, and you shut up, you listen. More like 
trying to ask them". She also clarified that questions are important in order to find what visitors can relate to. Lia makes the dialogue a choreographic tool: she normally asks tourists if they have ever seen a tree like a pine, and she build up her story based on their answer. Previous experience, memories and identities of the tourists are something Lia works with, during guiding, to bring visitors "to think about their everyday life, and try to get them to connect [...] and if you can get them to connect to things that they know already, then it is much easier". This happens, for instance, when she asks tourists is they have similar trees at home. Co-creating, more than reflecting simple engagement, helps in brokering empathy, creating a participatory environment, but also in facilitating reflections on the intimate relations between participants' lifeworld and nature (Hansen \& Mossberg, 2017; Reisinger \& Steiner, 2008; Christie \& Mason, 2003). Lia also cares dearly to encourage reflections after the tour is over: "when they come back, sometimes we ask them [...] what's going on in your mind, right now? [...] what is it that you took with you from this?" and she hopes for answers that reflect environmental awareness, humbleness and understanding. She stressed how these things are intimately connected, as knowledge alone is not enough: "all of us sees different things, and emphasize different things, but we all aim in the end is to get people to open their eyes to how do we live on the Earth today. Maybe we can change it, and maybe I can have a part in that."

Once arrived at Old Tjikko, participants of guided tours usually stops at the feet of the tree to have a Swedish "Fika", essentially a relaxed coffee/tea break with buns and sweets. Alex underlines that the fika is normally an occasion to encourage dialogues: "during the fika time, they have time to think about what they have heard during the tour, they can talk with each other, come up with some questions which they did not think about, while going through the guided tour". Yet, this is also a time for shared reflections on the theme of Alex's tour, time: "looking at Old Tjikko and thinking, woow, 10,000 years".

Despite her strong background as a naturalist, Lia is open to contributes from members of the group that might hold better expertise. For instance "if they are really expert in some sorts of birds or whatever, then I usually step back, and say, yeah, I know the most common birds we have here, but if a bird flies by [...] then you can sort of help out". However, the issue is "when there are people who are actually wrong on something, and they stress that, that's the biggest challenge”. Then the attempt to achieve a dialogical situation is challenged. Despite the literature stresses how, in a co-creative environment, it is challenging to "care for and focus on each individual's involvement and meaning creation" (Hansen \& Mossberg, 2017, p.274), Lia stresses that dealing with disagreement is even more challenging than co-creating the experience with a group composed by different backgrounds and generations. The reason is not that it is complicated to manage people in disagreement, but because the guide risks to lose leadership on her story and its aims. Lia does not co-create her tour with participants to pursue satisfaction or to simply "enhance" the tour, but as a strategy to bring the tourists to achieve a transformative goal, throughout a story that build on her knowledge, activism and background. If the leadership of the guide is challenged on this story (she particularly stresses disagreements over the environmental impact of forestry), then her position is weakened, and sometimes it leads to situations in which a person in disagreement over something significant "influences the whole group". In such situation, Lia either invite the participant to speak 
about the issue when the tour is over or, if required, politely opposes him/her: "Yeah, but the recent research says that". Lia is neither a neutral ambassador, a service deliverer or a mediator of the forest. Although being a co-creator and a listener, she is also a leader and an agent (Christie \& Mason, 2003; Dahles, 2002; Hallin \& Dobers, 2012).

\section{Conclusion}

This chapter moved from resource- and activity-based definitions of nature-based tourism, and conceptualized nature-based tourism experiences as a value exchange about naturalness between tourists and experience brokers. Such exchange is often seen according to a cocreative dynamic, in which the suppliers as "brokers" are demanded to follow and attempt to adapt to mutating value-based demands in order to achieve competitiveness and memorability. Departing from extant literature over guiding, the theoretical background of the chapter illustrated different roles according to which the guide is defined, in relation to experiences and co-creation. According to these definitions, "transferrable" skills are developed to meet supposed tourist valuations of naturalness and seek satisfaction. These relate particularly to social, empathic and choreographic skills.

Conversely, the guide is presented in the chapter as a proactive interpretation leader and agent of change, not concerned merely to satisfy expectations, but to trigger transformations (Christie \& Mason, 2003). Strategies of experience choreography and edutainment are not driven by logics of product enhancement, but by personal values attached to forest environments, and by the intent to unveiling such values, otherwise hidden to the tourist's eye. "Soft" staging skills are deeply dependent on the guide's personal valuations of the forest, on a case-sensitive sense of place, scientific background or activism. These, in turn, are reflected in the way a forest area is interpreted and signified, value is conveyed and the guiding enacted. Discourses are consequently formed about the old-growth forest, humanity and their relation to the environment. Throughout a personally valued pathfinding, the guide manages to establish a secure enclave, physically distant from other tourists, yet also symbolically far from the everyday life, in which tourists experience unusual and intense events and explore new ways of interpreting the landscape and create meanings (Hansen \& Mossberg, 2017). Consequently, the guide emerges as a relational and/or alternative guide (Bryon, 2012), transformational (Christie \& Mason, 2003), broker of knowledge, places, experiences and empathy through his/her choreography and pathfinding (Weiler \& Black, 2015), co-creator of meanings but also interpretation leader (Overend, 2012; Christie \& Mason, 2003). Ultimately, albeit not through the assessment of dimensions affine to SERVQUAL, the guide is able to reach the status of guide-plus (Hansen \& Mossberg, 2017).

I conclude that training and recruiting strategies for tourist guides in forest and natural areas should consider the guide's background and personal valuations of the environment as critical assets and determinants in experience brokering. In fact, the resulting guide performance has shown to be positive for the tourists, who never felt dissatisfied. Some felt transformed by the tour (although no evidence of the real consequences in the everyday life of the visitor could be gathered in this study). Yet, even those who did not were still able to find the means to cocreate their own value, to be empowered in the tour, and to add value due to the added knowledge and entertainment, the unexpected encounters, the possibility to create meaning and the involvement. The guide, at the same time, feels empowered and not commodified or 
alienated by expectations/satisfactions logic which would dominate and jeopardize the authenticity of his/her behaviour, his/her stories and valuations.

\section{References}

Andersen, S. and Rolland, C.G., 2018. Educated in friluftsliv-working in tourism: A study exploring principles of friluftsliv in nature guiding. Scandinavian Journal of Hospitality and Tourism, 18(4), pp.362-376.

Black, R., Weiler, B. and Chen, H., 2019. Exploring theoretical engagement in empirical tour guiding research and scholarship 1980-2016: a critical review. Scandinavian Journal of Hospitality and Tourism, 19(1), pp.95-113.

Bori-Sanz, M. and Niskanen, A., 2002. Nature-based tourism in forests as a tool for rural development: Analysis of three study areas in North Karelia (Finland), Scotland and the Catalan Pyrenees. Finland: European Forest Institute.

Bryon, J., 2012. Tour guides as storytellers-from selling to sharing. Scandinavian Journal of Hospitality and Tourism, 12(1), pp.27-43.

Campos, A.C. and Mendes, J., 2014. Oom do Valle, P., \& Scott, N.(2015). Co-creation of tourist experiences: A literature review. Current Issues in Tourism, 21, pp.1-32.

Clarke, V., Braun, V., \& Hayfield, N. (2015). Thematic analysis. Qualitative psychology: A practical guide to research methods, 222-248.

Cohen, E., 1985. The tourist guide: The origins, structure and dynamics of a role. Annals of tourism Research, 12(1), pp.5-29.

Cohen, E.H., Ifergan, M. and Cohen, E., 2002. A new paradigm in guiding: The Madrich as a role model. Annals of tourism research, 29(4), pp.919-932.

Dahles, H., 2002. The politics of tour guiding: Image management in Indonesia. Annals of Tourism Research, 29(3), pp.783-800.

Dickinson, J.E., Hibbert, J.F. and Filimonau, V., 2016. Mobile technology and the tourist experience:(Dis) connection at the campsite. Tourism management, 57, pp.193-201.

Ek, R., Larsen, J., Hornskov, S.B. and Mansfeldt, O.K., 2008. A dynamic framework of tourist experiences: Space-time and performances in the experience economy. Scandinavian Journal of Hospitality and Tourism, 8(2), pp.122-140.

Elmahdy, Y.M., Haukeland, J.V. and Fredman, P., 2017. Tourism megatrends, a literature review focused on nature-based tourism. MINA fagrapport, 32 .

Fredman, P., Wall-Reinius, S. and Grundén, A., 2012. The nature of nature in nature-based tourism. Scandinavian Journal of Hospitality and Tourism, 12(4), pp.289-309.

Galí, N. and Aulet, S., 2019. Tourists' space-time behavior in heritage places: Comparing guided and nonguided visitors. International Journal of Tourism Research, 21(3), pp.388-399. 
Gundersen, V.S. and Frivold, L.H., 2008. Public preferences for forest structures: a review of quantitative surveys from Finland, Norway and Sweden. Urban Forestry \& Urban Greening, 7(4), pp.241-258.

Hallin, A. and Dobers, P., 2012. Representation of space. Uncovering the political dimension of guided tours in Stockholm. Scandinavian Journal of Hospitality and Tourism, 12(1), pp.826.

Hansen, A.H. and Mossberg, L., 2017. Tour guides' performance and tourists' immersion: facilitating consumer immersion by performing a guide plus role. Scandinavian Journal of Hospitality and Tourism, 17(3), pp.259-278.

Hartman, S., Postma, A., Hessel Heslinga, J., Folmer, A., Papp, B., Wielenga, B., Lauments, A., Spiekermann, L., (2019). International market trends in nature based tourism. In: Tourism and Nature. Key Market Trends and Important Implications for SMEs. European Tourism Futures Report Nr.55.

Heintzman, P., 2009. Nature-based recreation and spirituality: A complex relationship. Leisure Sciences, 32(1), pp.72-89.

Io, M.U., 2013. Testing a model of effective interpretation to boost the heritage tourism experience: A case study in Macao. Journal of Sustainable Tourism, 21(6), pp.900-914.

Jensen, R., 2001. The dream society: How the coming shift from information to imagination will transform your business. McGraw Hill Professional.

Jonasson, M. and Scherle, N., 2012. Performing co-produced guided tours. Scandinavian Journal of Hospitality and Tourism, 12(1), pp.55-73.

Margaryan, L., 2017. Commercialization of nature through tourism (Doctoral dissertation, Mid Sweden University).

Overend, D., 2012. Performing sites: Illusion and authenticity in the spatial stories of the guided tour. Scandinavian Journal of Hospitality and Tourism, 12(1), pp.44-54.

Pine, B.J., Pine, J. and Gilmore, J.H., 1999. The experience economy: Work is theatre \& every business a stage. Harvard Business Press.

Gilmore, J. H., \& Pine, B. J. (2007). Authenticity: What consumers really want. Harvard Business Press.

Pond, K.L., 1993. The professional guide: Dynamics of tour guiding. Van Nostrand Reinhold Company.

Pröbstl, U., Wirth, V., Elands, B. and Bell, S., 2010. Good practice in european recreation planning and management. In Management of Recreation and Nature Based Tourism in European Forests (pp. 175-285). Springer, Berlin, Heidelberg.

Reisinger, Y. and Steiner, C., 2006. Reconceptualising interpretation: The role of tour guides in authentic tourism. Current Issues in Tourism, 9(6), pp.481-498.

Schmitt, B., 1999. Experiential marketing. Journal of marketing management, 15(1-3), pp.5367. 
Stokowski, P.A., 2000. Assessing social impacts of resource based recreation and tourism. Trends in outdoor recreation, leisure and tourism., pp.265-274.

Valkonen, J., Huilaja, H. and Koikkalainen, S., 2013. Looking for the right kind of person: Recruitment in nature tourism guiding. Scandinavian Journal of Hospitality and Tourism, 13(3), pp.228-241.

Varley, P. and Semple, T., 2015. Nordic slow adventure: Explorations in time and nature. Scandinavian Journal of Hospitality and Tourism, 15(1-2), pp.73-90.

Vespestad, M.K. and Lindberg, F., 2011. Understanding nature-based tourist experiences: An ontological analysis. Current Issues in Tourism, 14(6), pp.563-580.

Weiler, B. and Black, R., 2015. The changing face of the tour guide: One-way communicator to choreographer to co-creator of the tourist experience. Tourism Recreation Research, 40(3), pp.364-378.

Weiler, B. and Davis, D., 1993. An exploratory investigation into the roles of the nature-based tour leader. Tourism Management, 14(2), pp.91-98.

Weiler, B. and Ham, S.H., 2001. Tour guides and interpretation. Encyclopedia of ecotourism, pp.549-563.

Zillinger, M., Jonasson, M. and Adolfsson, P., 2012. Guided tours and tourism. Scandinavian Journal of Hospitality and Tourism, 12(1), pp.1-7. 